\title{
The migration of electronic commerce (EC): from planning to assessing the impact of EC on supply chain
}

\author{
Benjamin P.-C. Yen \\ School of Business, The University of Hong Kong, Hong Kong \\ Elsie 0.S. Ng \\ Department of Industrial Engineering and Engineering Management, \\ The Hong Kong University of Science and Technology, Kowloon, Hong Kong
}

\section{Keywords}

Electronic commerce,

Suppy chain management,

Business process re-engineering

\section{Abstract}

It has been an increasing trend for companies to migrate their businesses onto or publicize themselves on the Internet. Business process reeng ineering (BPR) is applied to migrate the business processes of the supply chain onto the Web. Such migration may cause some of the processes merged together. minimized or transformed into other processes within a supply chain. Therefore, careful planning for such migration with technical requirements is necessary. This paper starts with the review of related research on $B P R$, migration of supply chain onto the Internet, and the impact analysis of the migration. A thorough overview of how BPR can change each process of the supply chain onto the Internet is discussed. The main contribution of this paper is a framework of the electronic commerce (EC) impact on the supply chain and the measurement of impact. An industrial example is used to illustrate the evaluation as a result of EC deployment.

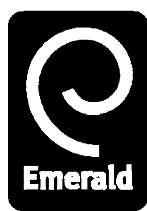

Management Decision 41/7 [2003] 656-665

(C) MCB UP Limited

[ISSN 0025-1747]

[DOI 10.1108/00251740310495586]

\section{Introduction}

The traditional market of electronic commerce (EC) was founded along with the rapid growth of the Internet. By 1995, EC began to mature with the emphasis of a variety of secure transaction processing services, and EC has been an increasing trend for companies to publicize their businesses on the Internet in order to increase their visibility as a business norm as well as to sell on the Internet (Westland and Clark, 1999). Vigoroso (1999) pointed out that suppliers who do not or will not develop Internet visibility in the near future would lose business competitiveness.

What are the reasons for the individual companies to invest such a vast amount of time and money into this new business strategy of migrating their businesses onto the Internet? Are they because these companies want to sell on the Internet in order to increase sales, or are they just following it as a competitive business norm to establish their visibility in the electronic market? With whatever reasons they bear, they are gradually moving the processes of supply chain (SC) such as sourcing, negotiating with suppliers, and coordinating with research and development (R\&D) onto the Internet. Thus, the term electronic supply chain (e-SC), electronic marketing (e-marketing), electronic procurement (e-procurement), and electronic logistics (e-logistics) have recently been invented to describe these activities that are taking place in the electronic market. E-SC results in greater control and flexibility along with cost savings in the SC operations, and provides suppliers the ability to become more proactive in the way they do business.

EC can be summarized as the buying and selling activities of information, products, and services via computer networks (Kalakota and Whinston, 1996). Strader et al. (1999) introduced a framework by simulating convergent assembly SC with information-sharing strategies with EC, so that information can be facilitated among supplier parties which results in a reduction of inventory cost and a minimized order fulfillment cycle time. Craig et al. (2000) suggested that e-business provides better value to customers by enhancing the relationship among different parties. Christiaanse and Zimmerman (1999) discussed the requirements and challenges for potential companies to adopt electronic channels and how KLM, a Dutch cargo company, applies electronic channels to reduce costs and improve responsiveness among several different parties. Loebbecke et al. (1999) illustrated how the largest academic bookseller, Co-op Bookshop, launched EC with difficulties in global competition and provided guidelines for the resources required to set up and maintain a Website to integrate the existing business into the Internet. Matsuda (2000) investigated the barriers for the adoption of the Japanese electronic market system (EMS) by examining the current status of the market and suggested a way to implement EMS under such market.

In addition to the adoption of the Internet, many companies have also decided to migrate part of or the whole SC onto the Internet. There are definite benefits that companies can gain from migrating their businesses onto the Internet; however, before they have launched the Internet, careful planning of the migration is necessary. For instance, Srinivasan et al. (2000) pointed out that by migrating the SC onto the Internet, both the key players and organizational activities would be adjusted, accompanied by both challenges and opportunities. Sadeh 
Benjamin P.C. Yen and Elsie O.S. Ng The migration of electronic commerce (EC): et al. (2000) illustrated how the SC could launch EC with their proposed system, "Multi-Agent Supply Chain cO-ordination Tool" (MASCOT) which results in the enhancement of real-time planning and scheduling functions throughout the whole SC, in order to achieve a more effective and efficient way to coordinate production and transportation. "The Swatch Group" migrated their SC onto the Internet while their transaction functions can be facilitated with the automated information flow within the SC and efficient communications between buyers and sellers (Alt et al., 2000).

Huang (1997) introduced a two-dimensional framework for the impact of EC on companies and society with the issues of technology and human. Choudhury et al. (1998) illustrated that e-marketing results in reduction in searching cost that allows buyers to search for market information more extensively and reduction in sellers' ability to obtain monopolistic profits, increased competition, and lower prices. Croom (2000) carried out a Delphi study to explore the impact of Web-based procurement systems on maintenance, repair, and operating (MRO) purchasing. Gebauer et al. (1998) studied the impact of the Internet on the procurement; in particular, the transaction process of a purchasing department focusing on the impact of buyer-supplier relationships over the Internet. Rhodes and Carter (1998) discussed the impact of EC on changing the product distribution in the textile apparel sector in globalization of production and retailing, evolution in retailing, evolving patterns of competition, pressures on SMEs, customization, and production of "batch of one".

The degree to which different companies wanted to get involved with EC varies; therefore, any company that migrates its processes of SC onto the Internet does not need to adopt EC completely. From the research done by Hong Kong Shippers' Council (2000), the components of e-SC have been further developed as e-marketing, e-procurement, and e-logistics. A lot of research has centered the business process reengineering (BPR) in procurement migration onto the Internet. By re-engineering the business processes of SC, the migration of the processes from the conventional trade to EC may result in a direct information and material flow from one entity to another in the electronic-based SC, while the intermediates are dis-intermediated or re-intermediated from the traditional trade. Hence, some or all of the business processes of SC may also be changed, merged together, or diminished. Apart from the migration of the SC onto the Internet, the objective of this paper studies the impact of EC on SC to investigate any drawbacks as well as benefits within the SC of EC in order to improve the current situation and to minimize any uncertainties incurred during the migration.

\section{The migration of supply chain onto the Internet}

Although the potential for value creation is enormous, migrating SC from traditional to EC is not straightforward, and some of the transitions may fail because the new processes are not carefully planned. The three major technical requirements for the migration of SC onto the Internet are system, enabling, and workforce. The system requirement includes mainly the information systems such as database for information storage and Web server applied in the EC applications as back-end and front-end systems. The enabling requirement consists of enabling technology, such as security standards/technology for protecting the Web server, digital cash for payment, and Internet access/service for EC applications. The workforce requirement is the extension of IT manpower for EC applications that includes mainly the skills, staff, training, and maintenance (Yen and Ng, 2002). Damsgaard and Scheepers (2000) introduced a four-stage model, initiation, contagion, control, and integration, for intranet implementation and management. Each stage is composed by seven elements: strategy, structure, systems, staff, style, skills, and super-ordinate goals. The four-stage model has further developed a ten-step migration procedure with a list of requirements, such as cost, time, and skills for each step of the migration as well as the migration steps. Since the degree of uncertainties increases with each successive step, therefore managers should conduct these steps carefully in order to minimize any risks of failure during the migration (Yen and Ng, 2003). Before a change decision is made, the systems analysis stages (Steps 1 and 2) are necessary to study the current status of the company to investigate any current problems within the system and to decide whether there is a need for a change. If there is a need for a change, Step 3 is applied to decide what to change and estimate for the amount of money and time needed. Steps 4 and 5 are the management stage, where the managers are responsible to re-allocate new tasks to each worker and to educate and guide them in order to minimize their 
Benjamin P.C. Yen and Elsie O.S. Ng The migration of electronic commerce (EC):

Management Decision 41/7 [2003] 656-665 uncertainties during the changes. Steps 6 to 9 are the implementation stage, which describe how to digitize the paper-based file system, build an inter-organizational communication infrastructure and the front-end EC system and to co-operate with third parties to extend the EC system into a portal. Finally, Step 10 is the maintenance stage, which is necessary for any system to follow the fast growing technology.

The four-phase implementation model, as shown in Table I, is illustrated with technical, security, and financial requirements. The four phases emphasize on the information flow within the migration process: information storage and retrieval, information transfer/exchange, information processing in EC, and with third party co-ordinations. The degree of expertise, intangible costs, complexity of information, security, and uncertainties increase from phase one to phase four.
Re-engineering the business processes will gain economic power and competitive advantage; for example, reduction in total cost and cycle time, enhancement in communication between different parties, and minimization of inventory and paper work at all levels (Laaper, 1998). Migration of $\mathrm{SC}$ onto the Internet requires a large amount of investment in terms of manpower and money. Therefore, in order to minimize the risks of failure, it is important to decide and plan carefully what have to be changed and what to achieve. The migration of the business processes in SC onto the Internet and how each business process can be changed will be discussed in the following. Please refer to Ng (2001) for the details with the corresponding technical requirements:

1 Marketing. In the conventional marketing, sellers send product information or catalogue to their target customers by postal mail and advertise in magazines, radio and TV. In the EC,

\section{$\overline{\text { Table I }}$}

The four-phase implementation model

\begin{tabular}{|c|c|c|c|c|}
\hline \multirow[b]{2}{*}{ Phase } & \multirow[b]{2}{*}{ Features } & \multicolumn{3}{|c|}{ Requirements } \\
\hline & & Technical & Security & Financial \\
\hline $\begin{array}{l}\text { First phase - digitization of } \\
\text { data }\end{array}$ & $\begin{array}{l}\text { Information storage and } \\
\text { retrieval } \\
\text { Convert paper-based file } \\
\text { into digitized and } \\
\text { automated information } \\
\text { system } \\
\text { Focus on Information } \\
\text { content with LAN within } \\
\text { the company }\end{array}$ & $\begin{array}{l}\text { Basic computer hardware } \\
\text { and software } \\
\text { Database system } \\
\text { LAN within the company } \\
\text { Basic computer skills }\end{array}$ & $\begin{array}{l}\text { Basic authentication rights } \\
\text { Firew alls }\end{array}$ & $\begin{array}{l}\text { Cost for hardware and } \\
\text { software } \\
\text { Training fees } \\
\text { Setup/maintenance costs }\end{array}$ \\
\hline $\begin{array}{l}\text { Second phase - building of } \\
\text { inter-organizational } \\
\text { comm unication } \\
\text { infrastructures }\end{array}$ & $\begin{array}{l}\text { Information } \\
\text { transfer/exchange } \\
\text { Inter-organizational } \\
\text { connections/inter- } \\
\text { communications: } \\
\text { connect and enhance } \\
\text { communications with } \\
\text { other companies through } \\
\text { e-mails and EDI }\end{array}$ & $\begin{array}{l}\text { Hardware and softw are for } \\
\text { Internet access and EDI } \\
\text { Network and computer } \\
\text { server for e-mail system } \\
\text { Further training }\end{array}$ & $\begin{array}{l}\text { A more sophisticated } \\
\text { firew all to protect EDI, } \\
\text { e-mail, and LAN }\end{array}$ & $\begin{array}{l}\text { Start up and subscription } \\
\text { costs for Internet access } \\
\text { Training fees } \\
\text { Costs for EDI and e-mail } \\
\text { system } \\
\text { Setup/maintenance costs }\end{array}$ \\
\hline $\begin{array}{l}\text { Third phase - } \\
\text { implementation of EC } \\
\text { front-end system }\end{array}$ & $\begin{array}{l}\text { Information processing } \\
\text { in EC } \\
\text { Implement the Web site } \\
\text { with functions such as } \\
\text { search engines, } \\
\text { chatrooms and message } \\
\text { boards }\end{array}$ & $\begin{array}{l}\text { Hardware and software for } \\
\text { EC front-end system } \\
\text { Technical staff with EC } \\
\text { knowledge }\end{array}$ & $\begin{array}{l}\text { Membership schemes } \\
\text { Firew all to protect EC } \\
\text { front-end system }\end{array}$ & $\begin{array}{l}\text { Costs for technical and EC } \\
\text { consultants } \\
\text { Cost for equipment and } \\
\text { staff of development } \\
\text { Setup/maintenance costs } \\
\text { for EC infrastructure }\end{array}$ \\
\hline $\begin{array}{l}\text { Fourth phase - integration } \\
\text { of vertical portal }\end{array}$ & $\begin{array}{l}\text { Information processing in } \\
\text { EC with third party } \\
\text { co-ordinations } \\
\text { Form portal to integrate } \\
\text { chain with third party for } \\
\text { transaction and logistics } \\
\text { functions and logistics } \\
\text { department }\end{array}$ & $\begin{array}{l}\text { Infrastructure for the } \\
\text { co-ordinations with third } \\
\text { party } \\
\text { Technical staff with EC } \\
\text { knowledge }\end{array}$ & $\begin{array}{l}\text { Data encryption and firew all } \\
\text { A more complicated } \\
\text { authentication model }\end{array}$ & $\begin{array}{l}\text { Transaction charge for third } \\
\text { party } \\
\text { Setup/maintenance costs } \\
\text { for EC infrastructure }\end{array}$ \\
\hline
\end{tabular}


Benjamin P -C. Yen and Elsie O.S. Ng The migration of electronic commerce (EC):

Management Decision 41/7 [2003] 656-665 e-mail is widely used to direct product and promotion information to target

customers. On the other hand, advertisements in the form of banners are provided in some Websites to allow customers to click and find out more about their products and, hence, customers' buying behaviour can be kept track of. Some of the sellers may also offer free digital coupons to purchase the product when the customers click on the appropriate banner.

2 Sourcing. In the conventional sourcing, sellers provide the information of goods in paper-based catalogues. In the EC, e-catalogues are provided on the Internet instead. Sellers no longer need to print paper-based catalogues, but instead, e-catalogues are developed to allow buyers to source for product information on the Internet conveniently. In addition, search engines, possibly with image as well as text search functions, are implemented in the shopping Website to provide buyers with fast and precise information on the desired goods.

3 Quotation. With the EC, buyers no longer obtain quotations through phone or fax, but, instead, online inquiry forms are provided in the shopping Website for them to fill in and request for a quotation. Then, in return, sellers will provide the buyers with quick and customizable quotations through electronic mail in a fast and timely way.

4 Negotiation. Similarly, electronic mail, chat rooms, or message boards are used to exchange information during negotiation between buyers and sellers without the need of negotiating through phone calls or faxes or even meeting face-to-face with each other.

5 Order placement. In the conventional trade, when an order decision is made, a purchasing order is prepared manually and faxed or sent by mail to the suppliers. With the EC, order placement is done through the restorable electronic order form. An electronic mail notifying the receipt of the order will be generated and sent to the buyer automatically once the form is submitted with a "click" on the button. All these are done within a few minutes that save cost, time, and all the paper work.

6 Transaction. Transaction which happens soon after order placement and payment information is usually required in the electronic order form. Therefore, order placement and transaction that happen one after the other can be merged together as the corresponding information for both processes are required in the same electronic order form. Money is collected either electronically using electronic money, such as electronic cash, or via credit card transactions like in the conventional trade with the card information required in the online order form. With the electronic money, payment is collected in timely, fast, and secure fashion.

7 Delivery. Just-in-time (JIT) delivery is attempted within an e-SC when the material is directed from sellers to buyers, provided that the delivery information such as shipping method, time, and location is given to the logistics soon after the transaction process is completed. In other words, delivery of goods is separated from the entire information-oriented SC (from marketing to transaction), while inventory is undercontrolled in the EC with JIT delivery. The third-party logistics coordinates closely with shipping companies and warehouses of manufacturers or distributors that enhances the information exchange among these parties. Such information includes time, location, and transportation mode of delivery.

\section{The framework of EC impact on supply chain}

EC focuses on the process improvement of inter-organizational transactions, unlike supply chain management (SCM), which concerns the material and information flow coordination. An analysis of EC and SCM reveals a complementary relationship with some overlapping - EC concentrates on shaping information and contracting activities, and SCM primarily focuses on planning process and the organization of various flows (Alt et al., 2000). From the research of the impact of EC on SC, a two-dimension table as a planning or brainstorming purpose illustrates the impact of buyers and sellers with respect to the business processes of SC, with the SWOT analysis, classifying the EC impact as strengths, weaknesses, opportunities, and threats. Strengths and weaknesses are for measuring the internal performance of the procurement process, i.e. efficiency and effectiveness, while external opportunities and threats are identified in the electronic environment that the SC is operating (Henderson et al., 1994). In order to minimize such weaknesses and threats as well as to maximize the benefits that we can gain from 
Benjamin P.C. Yen and Elsie O.S. Ng The migration of electronic commerce (EC):

Management Decision 41/7 [2003] 656-665 the migration, careful planning is essential (Yen and Ng, 2003). The categorization of impact of EC on SC is further developed from the preliminary impact while neglecting the negative impact. The impact is classified as buyer and seller, and then it is further categorized as individual and interorganization. Individual and interorganization classifications represent the internal efficiency and external impact, respectively.

From the research on the impact of EC on SC (Gebauer et al., 1998) and the categorization of impact, time, cost, inventory, product quality, satisfaction, value, and information have been gathered as the major measurements for the impact as shown in Table II. Time, cost, and inventory are the quantitative factors that mainly refer to the internal efficiency of the SC in which managers use them to analyze the result of the migration. Managers measure quality, satisfaction, and value mainly to find out how customers perceive the product and service they receive in order to have them come and shop again. The first six equally important factors to measure the impact of EC on SC are time, cost, and inventory, as the indication of internal efficiencies of the SC, and quality, satisfaction, and value as the indication of how customers perceive the product and services received. The seventh factor, information, can be included in the quality issue or measured as an independent factor.

1 Time. As a whole, time is reduced when the SC is being shortened during the migration onto the Internet in the form of information reach, flow or exchange between buyer and seller, such as enquiry time and cycle time. The processes are operating more efficiently as well as minimizing time within the SC; to measure the total amount of time saved in the migration of SC onto the Internet systematically, from the first to the last business process of the SC.

2 Cost. Sometimes cost cannot be measured separately from time as they are often related to each other. Therefore, when the amount of time that can be reduced within the operation of SC is measured, it can be interpreted as the amount of overall cost saved. In addition to the material cost, the overall cost will be saved not only because of the improved efficiency of the operation, but also from the decreased return rate of goods. Similar to time, cost can be measured systemically by the amount of money saved during a cycle of SC in terms of the unit of dollar (\$).

\section{Table II}

A summary of the impact factors

\begin{tabular}{|c|c|c|c|}
\hline Impact factor & Measuring period & Parties involved & Measurement mode \\
\hline Time & $\begin{array}{l}\text { Time saved in a supply chain cycle: } \\
\text { from marketing to delivery }\end{array}$ & Buyers and suppliers & Hours and minutes \\
\hline Cost & $\begin{array}{l}\text { Cost saved in a supply chain cycle: } \\
\text { from marketing to delivery }\end{array}$ & Buyers and suppliers & Dollars \\
\hline Inventory & $\begin{array}{l}\text { A supply chain cycle: from marketing } \\
\text { to delivery }\end{array}$ & Suppliers and shipping body & The amount of stock \\
\hline \multicolumn{4}{|l|}{ Quality } \\
\hline Product & $\mathrm{N} / \mathrm{A}$ - referring to the item itself & Buyers & $\begin{array}{l}\text { Measurement scales with eight attributes: } \\
\text { performance, features, reliability, conformance, } \\
\text { durability, serviceability, aesthetics and } \\
\text { perceived quality }\end{array}$ \\
\hline Service & $\mathrm{N} / \mathrm{A}$ - referring to the service itself & Buyers & $\begin{array}{l}\text { Measurement scales with five attributes: } \\
\text { tangibles, reliability, responsiveness, } \\
\text { assurance and empathy }\end{array}$ \\
\hline \multicolumn{4}{|l|}{ Satisfaction } \\
\hline Customers & $\begin{array}{l}\text { A supply chain cycle: from marketing } \\
\text { to delivery }\end{array}$ & Buyers & $\begin{array}{l}\text { Measurement scales with five attributes: } \\
\text { physical product characteristics or service } \\
\text { features, benefits wanted, personal imagery, } \\
\text { company imager and ultimate personal goals }\end{array}$ \\
\hline Sellers job satisfaction & $\begin{array}{l}\text { A supply chain cycle: from marketing } \\
\text { to delivery }\end{array}$ & Suppliers & $\begin{array}{l}\text { Measurement scales with five attributes: work, } \\
\text { pay, promotion, supervision and cow orkers }\end{array}$ \\
\hline Value & $\begin{array}{l}\text { A supply chain cycle: from marketing } \\
\text { to delivery }\end{array}$ & Suppliers & $\begin{array}{l}\text { The amount of profit in unit of dollars = total } \\
\text { revenue - total cost }\end{array}$ \\
\hline Information & $\begin{array}{l}\text { A supply chain cycle: from marketing } \\
\text { to delivery }\end{array}$ & Buyers and suppliers & Relevancy, accuracy, timeliness \\
\hline
\end{tabular}


Benjamin P -C. Yen and Elsie O.S. Ng

The migration of electronic commerce (EC):

Management Decision 41/7 [2003] 656-665
3 Inventory. Inventory can be reduced with the migration of SC onto the Internet, mainly by minimizing the bullwhip effect, the magnification of demand fluctuation as orders move up the SC, which results in greater variance than actual orders at the point of sale (Lee, 1997). The shortened information and material flow resulting from the dis-intermediation of some parties along the SC and better coordination of orders across the SC in $\mathrm{EC}$, is responsible for minimizing the bullwhip effect. Fewer parties performing the forecasting of demand will be more accurate and lead to reduced lead-time, which will result in smaller variance of demand and lower safety stocks. The unit of item measures the amount of inventory in a given period of time within a cycle of SC.

4 Quality. Quality includes service and product quality. It is a subjective concept that is responsible for how the customers perceive it according to the price they paid for it. It does not necessarily mean the best quality, but it has to reflect the price it is worth. Some shopping sites offer product or service customization for individual customers. Since product quality is a subjective perception of customers that is defined as the fitness for use (Juran, 1974), it can be quantified with the eight attributes proposed by Crosby (1979) with measurement scales in a given period: performance, features, reliability, conformance, durability, serviceability, aesthetics, and perceived quality. Service quality involves three elements (Rust and Oliver, 1994): the service is composed of service "features" (Neslin, 1983); the service environment is the setting and props required to conduct the service (Bitner, 1992); and the service delivery is the way the service is provided (Bitner et al., 1990). The five attributes introduced by Parasuraman et al. (1998) can be applied to quantify customer perceptions of service quality with measurement scales as tangibles, reliability, responsiveness, assurance, and empathy in a given period of time.

5 Satisfaction. Satisfaction of both buyers and sellers is essential for sustaining profitability of the shopping Website. It includes customer satisfaction and sellers' job satisfaction. Customer satisfaction is responsible by the relationship between buyers and sellers and how well the sellers can fulfill the buyers' needs, product quality, delivery speed, and aftersales service. Staff is usually uncertain about the changes and, therefore, managers have the responsibility to guide, educate, and train them in conducting the changes. Customer satisfaction can be measured systematically according to the five attributes in a given period of time: physical product characteristics or service features, benefits wanted, personal imagery, company imager, and ultimate personal goals (Myers, 1988). On the other hand, job satisfaction can be measured systematically according to the five factors proposed by Smith et al. (1987) work, pay, promotion, supervision, and coworkers.

6 Value. Value is created when companies turn their e-SC into profit. The strategies to achieve value include achieving and maintaining a good relationship and collaboration with customers, providing high product quality, and increasing customer satisfaction. Therefore, in order to create value, managers are responsible for planning and sustaining these strategies and keeping track of the progress (Earle and Keen, 2000). Measuring value in terms of customer satisfaction is complicated by some intangible factors that cannot be easily quantified. Therefore, it can be measured by the amount of profit in unit of dollar (\$) of a company, which is the result of total revenue minus total cost in a year, while neglecting all the intangible factors.

7 Information. Relevancy, accuracy, and timeliness are the three most important examples of information quality. The streamline of information exchange provides the channel for each party to get the required information to avoid information scarcity or information overload. In addition, the advent of information technology (IT) improves the data entry and transmission and consequently, the information accuracy has been improved. Furthermore, IT also provides the platform for real-time and online data access for timely information retrieval and processing. There are other examples for information quality, such as accessibility, completeness, etc. (Ballou et al., 1998; Wang, 1998). The relevancy can be measured by the ratio of the related information and the total information received. The accuracy can be denoted as the ratio of the data volume of automated system and manual system. The timeliness can be measured in the relative frequency of data update. 
Benjamin P -C. Yen and

Elsie O.S. $\mathrm{Ng}$

The migration of electronic

commerce (EC):

Management Decision

41/7 [2003] 656-665

\section{tex}

\section{Case study: EC in a textile/garment industry}

The textile and apparel industry stands out as one of the most globalized industries in the world today. The apparel industry is a supplier-driven commodity chain led by a combination of retailers, contractors, subcontractors, merchandisers, buyers, and suppliers; each plays an important role in a network of SC, which spans from fibers to yarn, to fabrics, to accessories, to garments, to trading, and to marketing. Geographically, they span multi-continents and cut across regional and national boundaries. The SC of the textile industry involves product design and development, material sourcing and product manufacturing, product distribution, and retailing of products. The product and raw material sources development process has 45 days of lead-time with 60 per cent of the prototypes. From manufacturing to delivery to distributors, the lead-time is 30 days with a total of eight inventory turns annually. The delivery leadtime from the distributors to the retailers is 24 hours with 90 per cent of order fulfillment. Therefore, the whole SC process may at least take 76 days. The 1995 report of the Hong Kong Government Industry Department (1996), states that the raw material suppliers faced the problems of limited variety and availability. With the shrinking profit margin and the advent of modern computing communication networks, it is imperative that Hong Kong's textile and apparel industry should seriously consider establishing a cost-effective IT infrastructure to maintain their competitive edge (Yen and $\mathrm{Su}, 1997)$.

HKTAIGA trading online and its impact Hong Kong Textile and Apparel Industry Global Applications (HKTAIGA) is a project funded by the Hong Kong Government since 1994. The Government saw the need to provide an efficient communication channel for the small- and medium-sized enterprises (SMEs). There are four phases in the development of HKTAIGA in which each phase is an individual project, summarized as:

1 catalogue browser system in client/server architecture;

2 Web-based communication infrastructure;

3 electronic front-end system for SMEs; and

4 horizontal and vertical portals.

The first stage started with the name Hong Kong Clothing Information Network System (HKCAINS), in which the information system was only used within the company. HKTAIGA extended the communication channel to a global level in order to establish an inter-organizational communication. The third phase migrated the system onto the Internet and adopted EC. The last phase extends the system into a portal, which involves the collaboration with third parties, such as banks and courier companies for transaction and logistics activities.

The architecture of HKTAIGA is a combination of databases, client/server modules, and Web-based systems (Yen and $\mathrm{Su}, 1997)$. The EC front-end system connected is supported by Web browsers and the back-end system acts as a combination of a database server and a Web server. The client application provides various procurement functions and offers tools to catalogue products. The search engine supports both image and text search functions that consist of a combination of an image search engine, categorised product trees, and an Intranet keyword search mechanism. The tracking functions record usage patterns to identify the Web pages that are of major concern to individuals or groups (Yen, 2002). The first phase of HKTAIGA required ten workers to build a CD-ROM media to catalogue its product information that facilitates the storage and retrieval of such information. It involved 20 pilot companies with an investment of $\$ 1.01 \mathrm{~m}$ for nearly two years. The problem that occurred in the first phase was the delay in the distribution of CDs to the buyers, which affected the communication between buyers and sellers. Therefore, in the second phase, as the number of buyers and suppliers increased, HKTAIGA decided to build up a communication infrastructure to solve this problem and to enhance the information transfer/exchange between buyers and sellers. The third phase HKTAIGA targeted a migration of its communication channel onto the EC front-end so that suppliers can catalogue their product information on a Web site and the buyers view the information without any geographical restrictions. Not only for the use of information exchange, the fourth phase is extending the EC front-end infrastructure into a portal with transaction and logistics functions.

Since HKTAIGA was first launched on the Internet, it has accumulated a total of 1,206 members, in which 60.5 per cent and 39.5 per cent are sellers (write users) and buyers (read users), respectively. From the cost and benefit report conducted in December 2000, with participating companies, 45 per cent took one to six months to adopt HKTAIGA into their business, and 27.5 per cent took six months to 
Benjamin P -C. Yen and Elsie O.S. Ng The migration of electronic commerce (EC):

Management Decision 41/7 [2003] 656-665 a year and more than a year to adopt it. Both the read and write users require Internet to access and manage their database and EC functions. The Quick Response Center (QRC), a semi-government organization, has been organizing workshops, seminars, and conferences to provide training on installation and management. The report also indicated that the usage for the functions offered by HKTAIGA is 36 per cent, 55.5 per cent, 18 per cent, 91 per cent, 9 per cent, and 18 per cent for homepage generator, company search, cataloguing, product search, discussion board, and advertisement, respectively. As the transaction and delivery functions were not implemented in HKTAIGA, these two functions remain the same as conventional trade, which are arranged between buyers and sellers offline.

The cost and benefit report mainly illustrates the cost reduction by adopting HKTAIGA to justify the cost measurement. Table III illustrates the amount of cost reduction for five material suppliers and two buyers after adopting HKTAIGA. The majority of material suppliers had 0-10 per cent of cost reduction in product catalogue production, physical visit and presentation to clients, enquiries follow-up, and storage space.

\section{Lessons learned from HKTAIGA}

Since HKTAIGA is still in its infant stage, there is a lot of room for improvement along with the lessons:

- Computer infrastructure - the majority of companies in the textile industry in Hong Kong are SMEs. HKTAIGA provides an EC infrastructure for them to facilitate the communication among different parties. However, these SMEs have limited resources, e.g. computers and skills. Thus, the majority prefer to do business in the traditional way rather than through the Internet.

- Workforce - since the the textile and apparel industry is one of the oldest industries in Hong Kong, its workforce mainly involves an older generation of senior labor who are rather conservative. Most of them believe that they are comfortable with the traditional way of carrying out operations; therefore, they do not want to change the way of conducting operations with HKTAIGA.

- Marketing - there is a need to promote HKTAIGA to the SMEs of the textile industry in Hong Kong in order to minimize their uncertainties about HKTAIGA. Regular meetings with these SMEs to promote HKTAIGA and provide them with tutorials and training will help them build up their confidence with HKTAIGA.

\section{Discussion and conclusion}

The migration of the SC onto the Internet requires the changing of the business processes. Such migration may cause some of the processes to merge together, minimized, or transformed into other processes within the SC. Migrating the SC onto the Internet does not always result in positive impact, so careful planning is necessary. It is useful to estimate the EC impact on SC to decide whether to migrate onto the Internet. In addition to the guidelines with the migration of SC onto the Internet from planning to implementation, the ways to assess the impact of EC on SC is also discussed in this paper. Nevertheless, the size and nature of the company determine the migration process and the requirements involved may vary as well. HKTAIGA serves as a vivid example to illustrate the migration process and impact analysis. Although this paper cannot totally reflect the EC deployment feasibility, it provides guidelines to conduct an impact analysis in the SC.

Last but not least, the following gives possible future directions:

- Appling the 3-D and virtual reality based electronic catalogues can provide a more

\section{Table III}

The cost reduction of companies by adopting HKTAIGA

\begin{tabular}{lcccc}
\hline & \multicolumn{4}{c}{ Reduction of cost by percentage } \\
Business operation & $\mathbf{0 - 1 0}$ & $\mathbf{1 1 - 5 0}$ & $\mathbf{0 v e r} \mathbf{5 0}$ & N/A \\
\hline Material suppliers & & & & \\
$\quad$ Product catalogue production & 50 & 16.6 & 16.6 & 16.6 \\
$\quad$ Physical visit and presentation to clients & 50 & 16.6 & 16.6 & 16.6 \\
$\quad$ Order and request follow up & 50 & 16.6 & - & 33.4 \\
$\quad$ Storage space & 50 & 16.6 & 16.6 & 16.6 \\
Buyers & & & & \\
$\quad$ Material sourcing & 40 & 60.0 & - & - \\
Physical visit to suppliers & 80 & 20.0 & - & - \\
$\quad$ Storage space & 40 & 60.0 & - & - \\
\hline
\end{tabular}


Benjamin P.C. Yen and Elsie O.S. Ng The migration of electronic commerce (EC):

Management Decision 41/7 [2003] 656-665 vivid effect on product pictures in order to attract more read users.

- Conduct a feasibility study of the implementation guidelines with the potential companies that want to migrate their businesses onto the Internet for justifications.

- Conduct a survey or visit a company to gain a thorough understanding of how the company handles each process changed, the problems encountered during and after the changes, and how the company solves the problems.

- Conduct a usability study to investigate the impact of technology diffusion for EC applications in different industries.

- Study accessibility models, navigation analysis, and customization for improvement of information retrieval on the Internet.

\section{References}

Alt, R., Grünauer, K.M. and Reichmayr, C. (2000), "Interaction of electronic commerce and supply chain management - insights from 'The Swatch Group'”, Proceedings of 33rd HICSS.

Ballou, D., Wang, R., Pazer, H. and Tayi, G.K. (1998), "Modeling information manufacturing systems to determine information product quality”, Management Science, Vol. 44 No. 4, pp. $462-84$.

Bitner, M.J., Booms, B.H. and Tetreault, M.S. (1990), "The service encounter: diagnosing favourable and unfavourable incidents", Journal of Marketing, Vol. 54, pp. 71-84.

Bitner, M.J. (1992), "Servicescapes: the impact of physical surroundings on customer and employees", Journal of Marketing, Vol. 56, pp. 57-71.

Choudhury, V., Hartzel, K.S. and Konsynski, B.R. (1998), "Uses and consequences of electronic markets: an empirical investigation in the aircraft parts industry”, MIS Quarterly, Vol. 22 No. 4, pp. 471-507.

Christiaanse, E. and Zimmerman, R.-J. (1999), "Managing electronic channels: the KLM cargo cyberpets case", Journal of Information Technology, Vol. 14 No. 2, pp. 123-35.

Craig, J., Jutla, D. and Bodorik, P. (2000), "e-Business evaluation framework", Proceedings of SSGRR (Scuola Superiore G. Reiss Romoli) 2000, Rome.

Croom, S. (2000), "The impact of Web-based procurement on the management of operating resource supply", The Journal of Supply Chain Management, Vol. 36 No. 5, pp. 4-13.

Crosby, P.B. (1979), Quality is Free, McGraw-Hill, New York, NY.

Damsgaard, J. and Scheepers, R. (2000), "Management the crises in intranet implementation: a stage model", Information Systems Journal, Vol. 10, pp. 131-49.
Earle, N. and Keen, P. (2000), From .com to .profit Inventing Business Models that Deliver Value and Profit, Jossey-Bass, San Francisco, CA.

Gebauer, J., Beam, C. and Segev, A. (1998), "Impact of the Internet on procurement", Acquisition Review Quarterly, Vol. 14, Spring, pp. 167-81.

Henderson, S., Illidge, R. and Mchardy, P. (1994), Management for Engineers, Butterworth Heinemann, Oxford.

Hong Kong Government Industry Department (1996), 1995 Techno-economic and Market Research Study on Hong Kong's Textiles and Clothing Industries, Volume II: Hong Kong's Softgoods Industry in the Global Supply Chain, Kurt Salmon Associates, Hong Kong.

Hong Kong Shippers' Council (2000), e-Logistics in Supply Chain Development for Hong Kong, available at: www.tdctrade.com/shippers/11/ 01logistics/log_01.html

Huang, K. (1997), The Impact of Electronic Commerce, ACM SIGCPR, San Fransciso, CA.

Juran, J.M. (1974), Quality Control Handbook, 3rd ed., McGraw-Hill, New York, NY.

Kalakota, R. and Whinston, A.B. (1996), Frontiers of Electronic Commerce, Addison-Wesley, Reading, MA.

Laaper, B. (1998), Procurement Reengineering, PT Publications, West Palm Beach, FL.

Lee, H.L. (1997), "The bullwhip effect in supply chain”, Sloan Management Review, Vol. 38 No. 3, Spring, pp. 93-102.

Loebbecke, C., Powell, P. and Gallagher, C. (1999), "Buy the book: electronic commerce in the book trade", Journal of Information Technology, Vol. 14 No. 3, pp. 295-301.

Matsuda, T. (2000), "An invisible barrier to implement electronic market systems: a case study of the Japanese produce market", Proceedings of International Conference on Advanced in Infrastructure for Electronic Business Science, and Education on the Internet, SSGRR, L'Aquilla, July 31-August 6.

Myers, J.H. (1988), Segmentation and Positioning for Strategic Marketing Decisions, 5th ed., Prentice-Hall, Englewood Cliffs, NJ.

Neslin, S.A. (1983), "Designing new outpatient health services: linking service features to subjective consumer perceptions", Journal of Health Care Marketing, Vol. 3, pp. 8-21.

Ng, E.O.S. (2001), "From planning to assessing the EC impact on supply chain”, MPhil thesis, IEEM, The Hong Kong University of Science and Technology, Hong Kong.

Parasuraman, A., Zeithaml, V.A. and Berry, L.L. (1998), "SERVQUAL: a multiple item scale for measuring customer perceptions of service quality”, Journal of Retailing, Vol. 64 No. 1, pp. $12-40$.

Rhodes, E. and Carter, R. (1998), "Electronic commerce technologies and changing product distribution", International Journal of Technology Management, Vol. 15 No. 1/2, pp. 31-48. 
Benjamin P.C. Yen and Elsie O.S. Ng The migration of electronic commerce (EC):

Management Decision 41/7 [2003] 656-665

\author{
It is a pleasure to thank the \\ members of HKTAIGA \\ project for implementing \\ part of the system as in the \\ case study. This research is \\ sponsored by Hong Kong \\ ITDC (under grant AF/114/ \\ 96 and $A F / 13 / 98$ ) and by \\ Taran Eastman Ltd (under \\ grant TEIL 99/00.EG01).
}

Rust, R.T. and Oliver, R.L. (1994), Service Quality: New Directions in Theory and Practice, Sage, Newbury Park, CA.

Sadeh, N.M., Hildum, D.W. and Kjenstad, D. (2000), "Intelligent e-supply chain decision support", Proceedings of International Conference on Electronic Commerce, Seoul, pp. 124-32.

Smith, P.C., Balzer, W., Brannick, M., Chia, W., Eggleston, S., Gibson, W., Johnson, B., Jsephson, H., Paul, K., Reilly, C. and Whalen, M. (1987), "The revised JDI: a facelift for an old friend", The Industrial-Organizational Psychologist, Vol. 24, pp. 31-3.

Srinivasan, M.M., Reeve, J.M. and Singh, M.P. (2000), "E-business in the supply chain", Proceedings of International Conference on advanced in Infrastructure for Electronic Business Science, and Education on the Internet, SSGRR, L'Aquilla, July 31-August 6.

Strader, T.J., Lin, F. and Shaw, M.J. (1999), "Business-to-business electronic commerce and convergent assembly supply chain management", Journal of Information Technology, Vol. 14 No. 3, pp. 361-73.
Vigoroso, M. (1999), "Buyers prepare for brave new world of e-commerce", Purchasing, Vol. 126 No. 6, pp. S4-S12.

Wang, R. (1998), "A product perspective on total data quality management”, Communication of the ACM, Vol. 41 No. 2, pp. 58-65.

Westland, J.C. and Clark, T.H.K. (1999), Global Electronic Commerce: Theory and Case Study, MIT Press, Cambridge, MA.

Yen, B.P.-C. and Su, C.J. (1997), "Information technology infrastructure for textile and apparel industry in Hong Kong”,

International Journal of Electronic Markets, Vol. 7 No. 2, pp. 9-12.4.

Yen, B.P.-C. (2002), "Electronic commerce front-end in apparel supply chain", International Journal of Computers \& Industrial Engineering, Vol. 42, pp. 471-80.

Yen, B.P.-C. and Ng, E.O.S. (2002), "Migrating procurement onto the Internet", Electronic Commerce Research Journal, Vol. 2 No. 1/2, pp. 113-34.

Yen, B.P.-C. and Ng, E.O.S. (2003), "Impact of electronic commerce on procurement", Journal of Organizational Computing and Electronic Commerce. 